\title{
Religião em movimento: relações entre religião e
}

modernidade

\section{Roberta Bivar Carneiro Campos \\ (UFPE) \\ Eduardo Henrique Araújo de Gusmão (UFCG)}

\author{
RELIGIÃO E MODERNIDADE: PERSPECTIVAS DA SOCIOLOGIA \\ CLÁSSICA \\ No âmbito das discussões empreendidas pelos clássicos do pensamento social
} moderno, a temática da origem e dos efeitos da modernidade assume um papel fundamental. Se pensarmos na primeira geração de intelectuais identificados como sociólogos e os situarmos no contexto europeu do século XIX, constatamos que viviam numa época onde era necessário ter uma consciência das enormes mudanças trazidas pelo século XVIII e do seu impacto na sociedade.

O deslocamento de grandes populações campesinas para a cidade, por exemplo, gerou uma concentração de pessoas no espaço urbano cujo grau de intensidade nunca havia sido experimentado. A transição de um momento em que se cultivava a terra no campo para uma outra situação marcada pela produção mecanizada das fábricas introduziu estas populações em novos espaços de trabalho. Novas tecnologias que pertenciam a uma nova época foram geradas. A experiência humana do trabalho assumiu uma nova forma e uma nova aplicação. Neste processo, as pessoas renovaram o entendimento acerca de como a sociedade, como uma unidade, deveria ser regulada, ou seja, as velhas elites deveriam dar lugar aos novos mestres que surgiam.

As instituições que ao longo da história, haviam se petrificado em decorrência da repetição de padrões tradicionais, sofreram um colapso diante das pressões que a adaptação ao ritmo acelerado das mudanças exigia. A sociedade européia entrava num estágio de desenvolvimento sem precedentes. Uma palavra era suficiente para descrevê-lo: modernidade.

Nas análises que foram desenvolvidas com o intuito de compreender este momento da história, e cujo enfoque assumiu direcionamentos sociológicos, o fenômeno religioso ocupa um lugar privilegiado. Basta lembrarmos os estudos desenvolvidos por Karl Marx, Émile Durkheim e Max Weber. 
As suas teorias não consideraram a crença e o comportamento religioso, mesmo diante das pressões impostas pela modernidade, como hábitos humanos marginais. Apesar de estes intelectuais divergirem quanto as suas previsões acerca da trajetória futura das idéias e instituições religiosas, cada um guardava a convicção de que a análise da modernidade não podia deixar de considerar a importância da religião como um modelo e uma motivação para a ação humana.

Para Marx, a religião seria a principal forma de falsa consciência, ao evitar que as classes trabalhadoras de cada período histórico reconhecessem seus próprios interesses na revolta contra a classe proprietária. A religião constituiria um dos elementos, talvez o mais importante, da ideologia dominante, este conjunto de crenças que permeia a consciência da sociedade e que mantém os interesses da classe dirigente, fazendo com que a ordem social seja algo natural e inevitável. Na introdução de sua Crítica à Filosofia do Direito de Hegel, o mencionado autor colocava:

Religious suffering is, at one and the same time, the expression of real suffering and a protest against real suffering. Religion is the sigh of the oppressed creature, the heart of a heartless world, and the soul of soulless conditions. It is the opium of the people. (Marx 1977: 45)

Se tomarmos como exemplo os estudos de Max Weber, percebemos que a relação entre religião e modernidade traz consigo preocupações a respeito das origens da racionalidade moderna. Para este autor, a religião teria sido, por intermédio do Protestantismo da Reforma, o fenômeno social responsável pela erradicação dos elementos mágicos que compunham a realidade social européia, no período anterior à modernidade. Para além de um processo de racionalização religiosa, este movimento traria consigo as condições internas necessárias para o aparecimento e a consolidação do Capitalismo no Ocidente. Duas passagens da obra deste autor salientam esta relação. Em sua Sociologia da Religião, Weber afirma:

A criação de uma ética capitalista somente foi obra - ainda que não intencionada - do ascetismo intramundano do protestantismo, o qual abriu precisamente aos elementos mais piedosos e eticamente mais rigoristas o caminho à vida dos negócios e lhes apontava, sobretudo, o êxito nessa área como fruto de uma condução da vida racional. (Weber 1998: 391, 392)

Nas últimas páginas d’A Ética Protestante e o Espírito do Capitalismo, ao tratar da relação entre ascese cristã e capitalismo, Weber coloca:

Um dos elementos componentes do espírito capitalista moderno, e não só deste, mas da própria cultura moderna: a conduta de vida racional fundada na idéia de profissão como vocação, nasceu - como queria demonstrar essa exposição - do espírito da ascese cristã. (Weber 2004: 164)

Este processo de racionalização religiosa, ao eliminar progressivamente os elementos mágicos da religião, empreenderia para Weber uma jornada de racionalização em duas frentes: por um lado, a racionalização teórica, que confere um sentido unitário e coerente para o mundo, e por outro a racionalização prática, que orienta e informa aos agentes a sua conduta ética cotidiana. 
Nas análises de Émile Durkheim, o problema da religião na sociedade moderna está relacionado com as preocupações deste autor acerca das conseqüências morais da modernização sofrida pelas sociedades européias no início do século XX. O mencionado autor preocupava-se com as ameaças que poderiam advir da possibilidade de um individualismo amoral e descontrolado para a sociedade e o bem estar coletivo.

Conforme as suas análises, o fenômeno religioso constituiria, na sociedade moderna, uma força vital e unificadora. A religião exerceria uma espécie de função conciliadora entre os interesses da sociedade no bemestar coletivo e as crescentes demandas individuais por autodeterminação. Nesse sentido, para Durkheim, mais importante do que se preocupar com o desaparecimento da religião diante das forças da modernidade seria compreender a capacidade deste fenômeno em se transformar e adaptar-se à nova época. A questão fundamental para este autor dizia respeito assim ao novo formato assumido pela religião em um continente como a Europa, que vivenciava uma época pós-tradicional e industrializada.

Seria no fenômeno denominado de "culto ao indivíduo" ou "religião da humanidade" que Durkheim visualizaria formas de religiosidade mais adequadas para a sociedade européia contemporânea. Devido ao fato de a sociedade moderna se movimentar em direção a uma organização social geradora de uma solidariedade orgânica, o social e o religioso deixariam de ser sinônimos, e a religião passaria a englobar uma porção cada vez menor da vida social. Esta tendência está exposta no texto A Divisão do Trabalho Social da seguinte forma:

Originalmente, ela se estende a tudo; tudo o que é social é religioso, as duas palavras são sinônimos. Depois, pouco a pouco, as funções políticas, econômicas e científicas se emancipam da função religiosa, constituem-se à parte e adquirem um caráter temporal cada vez mais acentuado. Deus, se é que podemos nos exprimir assim, que antes estava presente em todas as relações humanas, retira-se progressivamente delas; ele abandona o mundo aos homens e a suas disputas. (Durkheim 1995: 151, 152)

Conforme o autor, em sociedades como aquelas da Europa Ocidental, a religião continuaria presente por intermédio de uma moralidade que atribuía ao indivíduo uma dignidade única. É também em A Divisão do Trabalho Social que Durkheim expõe este movimento, ao dizer:

À medida que todas as outras crenças e todas as outras práticas assumem um caráter cada vez menos religioso, o indivíduo torna-se objeto de uma espécie de religião. Temos pela dignidade da pessoa um culto que, como todo culto forte, já tem suas superstições. (Durkheim op. cit.: 155)

Para Durkheim, o aspecto de sacralidade e dignidade atribuído ao indivíduo estaria situado num processo evolutivo de longa duração. Por intermédio de uma criação e uma recriação contínua de si mesma, a sociedade desenvolvera novos ideais coletivos que expressavam uma consciência com novas aspirações. Neste contexto, a pessoa humana tornara-se o repositório definitivo para os ideais transcendentes da sociedade.

O que o mencionado autor testemunhava em seu tempo era a última fase da evolução do fenômeno religioso, definida como "moderna" por Robert Bellah em seu ensaio Religious Evolution. A modernidade, de acordo com Bellah, transformaria a vida social num fenômeno de infinitas possibilidades, e neste contexto, o homem seria responsável pela escolha de seu simbolismo. 
Portanto, o que as análises dos clássicos do pensamento social moderno deixam claro é que, se na aurora do homem, Deus estava presente em cada relação humana, na Europa de início do século XX a tendência que se apresentava era a de sua retirada, o que tornava o mundo um legado da humanidade e de seus conflitos, e a religião um fenômeno do âmbito privado.

Diante destas breves considerações acerca da relação entre religião e modernidade, podemos lançar a questão norteadora da discussão que é desenvolvida a seguir: como compreender esta relação no mundo de hoje?

\section{RELIGIÃO E MODERNIDADE HOJE: REFLEXÕES SOBRE OS CENÁRIOS DA RELIGIÃO NO MUNDO CONTEMPORÂNEO}

Ao concluir o ensaio acerca da evolução do fenômeno religioso, Robert Bellah tece considerações otimistas no tocante às possibilidades surgidas com o advento da modernidade. $\mathrm{O}$ traço marcante da situação atual do fenômeno religioso seria a liberdade cultural e individual dos sujeitos, no tocante à escolha que cada um faz a respeito da busca pelo significado. Nos termos de Robert Bellah, esta procura estaria cada vez menos inserida em contextos institucionais. Ao terminar o seu ensaio, Bellah chama a atenção para as possibilidades decorrentes da corrosão de velhas estruturas e práticas, em razão do modo de vida moderno. A modernidade ofereceria "unprecedented opportunities for creative innovation in every sphere of human action." (Bellah 1964: 373-374)

A discussão levantada por Robert Bellah estava situada em um intenso debate sobre as transformações sofridas pelo fenômeno religioso num contexto de avanço da modernidade, questão também tratada no livro $O$ Dossel Sagrado, de Peter Berger. No tocante ao livro de Berger, a principal preocupação do autor é compreender a religião como produto histórico, a partir de dois esforços: analisar a importância da religião no empreendimento humano de construção e manutenção do mundo e compreender o seu declínio ao longo da história ocidental moderna.

Ao tratar do declínio da religião, Berger expõe três fatores que teriam sido fundamentais neste processo: a individualização, ou seja, a tendência da religião a localizar-se cada vez mais na esfera privada da vida social, constituindo um assunto de escolha ou preferência do indivíduo ou do núcleo familiar; este processo, por conseguinte, ao situar a religião no nível das escolhas individuais, teria gerado um quadro de pluralismo, no qual as tradições religiosas disputariam as submissões de suas populações numa situação de mercado. Cada um destes fatores teria contribuído para o processo de secularização, definido como "o processo pelo qual setores da sociedade e da cultura são subtraídos à dominação das instituições e símbolos religiosos." (Berger 1985: 119)

Conforme a análise exposta no livro O Dossel Sagrado, o processo de secularização traria como conseqüência uma perda de autoridade da religião em nível institucional e em nível de consciência humana. Os rumos tomados pelo fenômeno religioso no futuro estariam diretamente relacionados com forças como pluralização e individualização, e também com o modo pelo qual a religião reagisse a estas forças. 
No âmbito da teoria social produzida por pesquisadores brasileiros, percebe-se que as discussões levantadas por Peter Berger influenciaram gerações de maneiras distintas. Se por um lado autores como Antônio Flávio Pierrucci e Reginaldo Prandi compreendem a relação entre religião e modernidade a partir do modelo de mercado religioso (Pierrucci \& Prandi 1996), estudiosos como Emerson Giumbelli (2002) e Patrícia Birman (2003) buscaram entender a relação do religioso com aquelas dimensões da vida social consideradas laicas, mais do que ler a religião através de uma "lógica secular".

O fato é que a temática da secularização ainda constitui um tema fundamental para os estudiosos do fenômeno religioso. Nos debates mais recentes, a relação entre religião e modernidade tem sido analisada a partir de uma preocupação com o desenvolvimento, na civilização ocidental cristã, de certos aspectos da modernidade tidos como seculares. É exatamente isto o que Charles Taylor examina no seu mais recente livro, $A$ Secular $A g e,$. O autor lança a questão: o que significa dizer que vivemos numa época secular? Ao tentar respondê-la, Charles Taylor apresenta uma compreensão do que seja o processo de secularização levando em consideração as modificações sofridas pela crença na sociedade moderna. O interesse do autor é examinar the conditions of belief em nossa sociedade. A secularização traria consigo uma mudança que implicaria, conforme o autor,

a move from a society where belief in God is unchallenged and indeed, unproblematic, to one in which it is understood to be one option among others, and frequently not the easiest to embrace. (Taylor 2007: 3)

No sentido levantado por Taylor, a mudança ocorrida envolve uma situação em que a fé é apenas uma possibilidade. Por mais inconcebível que seja para alguém o abandono de uma fé, esta possibilidade existe no mundo contemporâneo desde o século XIX. Taylor afirma que A crença em Deus não é mais axiomática. Ao falar de secularização, o autor chama a atenção para o contexto de entendimento no qual a nossa experiência moral, espiritual e religiosa é vivida.

O processo de secularização analisado por Taylor ocorre em uma sociedade em que, pela primeira vez na história, um humanismo auto-suficiente tornou-se uma opção amplamente disponível. Este humanismo não leva em consideração objetivos que ultrapassem os limites da realização humana. Neste sentido, o que Taylor entende por uma era secular é exposto da seguinte forma:

a secular age is one in which the eclipse of all goals beyond human flourishing becomes conceivable; or better, it falls within the range of an imaginable life for masses of people. This is the crucial link between secularity and a self - sufficing humanism. (Taylor op. cit.: 19, 20)

A tendência analisada por Charles Taylor tem consequências fundamentais para os direcionamentos assumidos pelo fenômeno religioso na contemporaneidade.

Primeiramente, estaríamos vivendo numa época marcada por uma ética da autenticidade. Trata-se de um momento de busca individual da espiritualidade, onde o foco recai sobre o indivíduo e em sua experiência. Taylor define este momento dizendo: "... this is a culture informed by an ethic of authenticity. I have to discover 
my route to wholeness and spiritual depht. The focus is on the individual, and on his/her experience. Spirituality must speak to this experience." (Taylor op. cit.: 507)

Nos relatos individuais a ênfase localiza-se em termos como "unidade", "integridade", "holismo" e "individualidade", com uma linguagem que frequentemente invoca imagens de "harmonia", "fluxo" e "integração". O autor salienta que neste contexto, a imagem mais recorrente nas experiências individuais é a da "busca", da "procura". E os relatos definem esta procura enquanto uma experiência espiritual, oposta às formas institucionalizadas de religião.

É através de uma tipologia de inspiração durkheimiana que Charles Taylor examina o contexto no qual surge esta ética da autenticidade 1 . Conforme o autor, o secularismo contemporâneo estaria marcado por traços de uma era pós-durkheimiana, na qual o absurdo não é apenas pertencer a uma igreja sem acreditar em seus ensinamentos, mas aderir a uma espiritualidade que não se apresente como um caminho que inspire e movimente o sujeito. O autor afirma:

Paleo-, neo-, post-Durkheimian describe ideal types. My claim is not that any of these provides the total description, but that our history has moved through these dispensations, and that the latter has come to colour more and more our age. (Taylor op. cit.:487)

É importante ressaltar que a idéia de espiritualidade que o autor menciona é constituída por elementos de pluralismo que não envolvem apenas perspectivas doutrinárias. Trata-se de um pluralismo cujos limites procedem de uma ordem moral que prioriza liberdades individuais e benefícios mútuos. Charles Taylor coloca:

Of course, this understanding of the place and nature of spirituality has pluralism built into it, not just pluralism within a certain doctrinal framework, but unlimited. Or rather, the limits are of another order, they are in a sense political, and flow from the moral order of freedom and mutual benefit. My spiritual path has to respect those of others; it must abide by the harm principle. With this restriction, one's path can range through those which require some community to live out, even national communities or would-be state churches, but it can also range beyond to those which require only the loosest of affinity groups, or just some servicing agency, like a source of advice and literature. (Taylor op. cit.:489, 490)

Em condições contemporâneas, a busca religiosa não está mais relacionada, pelo menos não mais numa forma predominante, com elementos de ordem paleo ou neo-durkheimianas, sejam estes uma igreja nacional ou o Estado. Atualmente, e aqui deveríamos mais uma vez citar Charles Taylor, the spiritual as such is no longer intrinsically related to society." (Taylor op. cit.: 490)

Poderíamos nos lembrar aqui da discussão levantada por Paul Heelas no seu livro The Spiritual Revolution. Para este autor, o traço mais emblemático da modernidade seria o que ele chama de the subjective turn. Numa aproximação muito clara com a discussão levantada por Charles Taylor, Paul Heelas evidencia uma disposição do sujeito contemporâneo em viver sua vida em torno de suas próprias experiências subjetivas, e de situar o sagrado no âmbito destas experiências. O autor define este processo da seguinte forma: "It is a turn away from 
life lived in terms of external or objective roles, duties and obligations, and a turn towards life lived by reference to one's own subjective experiences (relational as much as individualistic)." (Heelas \& Woodhead 2004: 2)

Ao tentar definir os traços do mundo contemporâneo, é justamente o aspecto pluralista da época atual que Charles Taylor destaca. A chamada era da autenticidade teria retirado da crença aquilo que a tornava algo óbvio e absoluto. O rígido vínculo normativo entre certa identidade religiosa, a crença em determinados postulados teológicos e uma prática correspondente já não envolve muitas pessoas. $\mathrm{O}$ autor é muito claro:

It is a pluralist world, in which many forms of belief and unbelief jostle, and hence fragilize each other. It is a world in which belief has lost many of the social matrices which made it seem "obvious" and unchallengeable. Not all, of course; there are still milieux in which it is the "default" solution: unless you have powerful intuitions to the contrary, it will seem to you that you ought to go along. But then we also have milieux in which unbelief is close to being the default solution (including important parts of the academy). So over-all fragilization has increased. (Taylor op. cit.: 531)

A ampliação da fragilização da crença mencionada por Charles Taylor constitui um ponto cuja relevância tem sido evidenciada pelos estudos de Danièle Hervieu-Léger. No livro O Peregrino e o Convertido, o aspecto salientado por Taylor faria parte de um processo amplo de "erosão do crer religioso institucionalmente validado" (Hervieu-Léger 2008: 170). O que caracteriza o tempo atual, conforme a análise de Hervieu-Léger não é a mera indiferença com respeito à crença, mas a perda de sua regulamentação por parte das instituições tradicionais produtoras de sentido. A autora indica este movimento dizendo que

as crenças se disseminam. Conformam-se cada vez menos aos modelos estabelecidos. Comandam cada vez menos as práticas controladas pelas instituições. Tais tendências são os maiores sintomas do processo de desregulação que caracteriza o campo religioso institucional no final do século XX. (Hervieu-Léger op. cit.: 50)

Conforme a análise efetuada por Danièle Hervieu-Léger, a crença destacaria também o caráter paradoxal da modernidade. Se por um lado, as grandes explicações religiosas do mundo sofrem um processo de desqualificação, por outro, esta mesma modernidade secularizada tem oferecido as condições mais favoráveis à expansão da crença. E este paradoxo define o processo de secularização que caracteriza o mundo moderno. Para a autora, ao falarmos de secularização, precisamos perceber

o conjunto dos processos de reconfiguração das crenças que se produzem em uma sociedade onde o motor é a não satisfação das expectativas que ela suscita, e onde a condição cotidiana é a incerteza ligada à busca interminável de meios de satisfazê-las. (Hervieu-Léger op. cit.: 41)

Ao relacionarmos as discussões de Charles Taylor e Danièle Hervieu-Léger, percebemos que em suas análises as sociedades modernas não são encaixadas numa perspectiva restrita de secularização, marcada pela idéia da privação social e cultural da religião. Em cada uma das críticas, o mundo moderno não é caracterizado pela ausência de religião, mas pelas dinâmicas de movimento, mobilidade e dispersão que marcam as inúmeras opções que surgem nesta paisagem religiosa de início de século. 
Neste sentido, se o elemento religioso, como aspiração ao absoluto, como busca de sentido numa interrogação sobre a morte, está muito longe de desaparecer, resta pensar o estatuto desse elemento - inquieto, problemático e incerto - num universo como o do Ocidente contemporâneo, marcado pela laicidade. É tendo este problema como ponto de partida que Luc Ferry e Marcel Gauchet buscam analisar o lugar ocupado pela religião na época atual. A discussão empreendida por estes autores envolve temas que também são tratados por Charles Taylor e Danièle Hervieu-Léger. Seria interessante tecermos considerações a respeito.

Luc Ferry se preocupa com o cruzamento de dois processos na época contemporânea: por um lado, o que o autor chama de "humanização do divino", ou seja, o fato de que toda a história cultural moderna consiste na produção dos conteúdos teóricos e práticos da religião na linguagem do humanismo ou, dito de outra forma, numa linguagem que seja compatível com o indivíduo, considerado um sujeito autônomo. Ao falar de humanização do divino, Luc Ferry estaria se referindo a um vasto movimento que caracteriza, desde o século XVIII, o crescimento da laicidade na Europa. No livro O Homem-Deus, o autor já se referia a este processo dizendo: “Em nome da recusa dos argumentos de autoridade e da liberdade de consciência, o conteúdo da Revelação não cessou de ser humanizado, no decorrer dos dois últimos séculos." (Ferry 2007: 52)

Um outro processo envolveria a "divinização do humano", isto é, o fato de que no âmago do individualismo autônomo moderno - um individualismo que é a característica mais emblemática do secularismo moderno, conforme evidenciado por Charles Taylor - a transcendência ressurge, não mais numa relação entre os homens e o além, mas entre os próprios homens. O humanismo contemporâneo seria um humanismo do homem-Deus.

Para Luc Ferry, o religioso, como “discurso que diz respeito ao elo entre o finito e o infinito, entre o relativo e o absoluto, com uma questão central: a da finitude ou, para ser mais preciso, da morte" (Ferry \& Gauchet 2008: 24), constituiria uma dimensão da existência humana com um potencial ainda incontornável e legítimo, mesmo no contexto da Europa Ocidental contemporânea. Um dos indícios desta persistência da religião seria, por exemplo, a permanência da noção de sacrifício entre nós, modernos, no âmbito das problemáticas morais. Esta noção não desapareceu. Como nota Luc Ferry, os seus motivos teriam sofrido um processo de humanização. O autor coloca:

... hoje na Europa não nos sacrificamos mais por entidades religiosas; mas, por outro lado, penso que inúmeros indivíduos estariam prontos a arriscar suas vidas para defender certos números de valores, ou, simplesmente, para defender seus próximos. Por que fazer esta constatação, que poderia parecer de uma banalidade consternadora, tenho consciência disso? Porque acho - e retomo aqui uma maneira nietzschiana de descrever o religioso ou o sagrado - que a partir do momento em que se estabelecem valores superiores à vida material, biológica, entra-se na esfera do religioso. (Ferry \& Gauchet op. cit.: 33)

Ou seja, a idéia de transcendência não desapareceu, de acordo com Luc Ferry. E ao falar de divinização do humano, o autor situa a idéia de sacrifício como algo inteiramente inerente à moral moderna. Caberia ao analista, portanto refletir sobre o que faz com que, numa sociedade globalmente materialista como a da Europa Ocidental, princípios superiores à vida ainda existam. ${ }^{2}$ 
Marcel Gauchet contesta a posição de Luc Ferry, considerando que uma interpretação radicalmente não religiosa da transcendência é possível. O autor persiste na idéia de que a época atual é a de um afastamento e de uma separação entre o homem e Deus que não cessa de se ampliar. Essa separação, atualmente, teria atingido sua amplitude máxima, de tal forma que o humanismo contemporâneo não seria apenas o do homem sem Deus, mas o do homem definitiva e irrevogavelmente sem Deus.

Para este autor, o aspecto mais relevante de nossa época é "a saída da estruturação religiosa das sociedades" (Ferry \& Gauchet op. cit.: 42), que traria como conseqüência o desgaste progressivo da eficácia estruturante do fenômeno religioso. Trata-se de um aspecto que Marcel Gauchet já apontara em livro anterior, como se pode ver na discussão levantada em The Disenchantment of the World, quando o autor utiliza o conceito de "saída da religião". É importante discutirmos este conceito, por um momento.

Ao se referir ao cristianismo, Gauchet utiliza esta idéia com a intenção de frisar o seu potencial laicizante. Esta religião, ao longo do amplo processo de desencantamento do mundo ocorrido no Ocidente, teria se transformado numa religião de "saída da religião" (Gauchet 1997: 04). Este ponto é importante para a discussão acerca da relação entre religião e modernidade: o conceito lançado por Gauchet busca ir além da constatação da perda de poder político e do enfraquecimento da influência social da Igreja, para expressar o mundo no qual a religião não é mais estruturante. Para Gauchet, o importante não é conceber uma sociedade dividida ou classificada entre um setor ainda vulnerável à influência da Igreja e os que superaram este estágio: o processo de saída da religião estaria ocorrendo numa sociedade na qual não só a religião deixou de ser estruturante, mas o próprio estatuto do sagrado teria sido transformado, e esta transformação seria uma conseqüência interna ao desenvolvimento do cristianismo, tendo seus efeitos acelerados pelo surgimento do Estado e o avanço da ciência.

Voltemos agora ao debate com Luc Ferry. De acordo com Marcel Gauchet, a partir de uma contraposição em relação à idéia de divinização do humano defendida por Luc Ferry, a idéia de sagrado já teria desaparecido da experiência contemporânea. O autor afirma:

Ora, se há uma categoria que o desencantamento do mundo deixa pouco à vontade, é bem essa. A "desmagificação" do mundo, que reteve prioritariamente a atenção, é inseparável de um processo de dessacralização, do qual se pode seguir historicamente a trajetória com grande precisão. (Ferry \& Gauchet op. cit.: 49)

Ao processo de humanização do divino definido por Luc Ferry, Marcel Gauchet contrapõe um movimento de "desantropomorfização" de Deus, no qual "Deus não nos é mais pensável, seja no abstrato da filosofia, seja no concreto existencial da crença, senão num trabalho para separá-lo ou afastá-lo da humanidade." (Ferry \& Gauchet op. cit.: 52) Ainda no tocante à divinização do humano, Marcel Gauchet apresenta a tese contrária de que, embora exista algo de absoluto no homem, não é da ordem do divino. Este absoluto seria humano, não demasiadamente humano, mas nada além de humano. A condição humana contemporânea seria aquela na qual deixamos "completamente de nos olharmos no espelho de Deus" (Ferry \& Gauchet op. cit.: 55). 
Apesar das divergências entre as posições de Luc Ferry e Marcel Gauchet, algo os aproxima: é a constatação de que vivemos um momento que acompanha uma saída da religião e uma individualização do crer. Esta convergência salienta um aspecto teórico muito importante: se os cenários pensados pelos dois filósofos franceses e as discussões efetuadas por Charles Taylor e Danièle Hervieu-Léger realmente representam as tendências contemporâneas do fenômeno religioso, então o retorno aos clássicos é algo de extrema importância. Afinal de contas, na véspera da $1^{\text {a }}$ Guerra Mundial, Émile Durkheim já visualizava as inclinações dos europeus a se identificarem com novos deuses e ideais, mais capazes de se adaptarem aos novos tempos. Em 1914, ao meditar acerca do futuro da religião, o autor afirmava:

Os velhos ideais e as figuras divinas que os corporificavam estão agonizantes, por que já não respondem mais adequadamente às novas aspirações que estão emergindo, e os novos ideais que serão necessários para guiarmos nossas vidas não existem. Nós nos achamos, portanto num período intermediário, de frieza moral, que explica os vários sintomas dos quais somos, em cada momento, as ansiosas, deprimidas ou tristes testemunhas... existe uma idéia a qual precisamos nos acostumar: é a de que a humanidade está abandonada neste mundo, deixada apenas com suas capacidades, e apta a confiar apenas em si mesma para dirigir o seu destino. Na medida em que se avança na história, esta idéia ganha mais terreno. E duvido, portanto que perca algum. À primeira vista, a idéia pode aborrecer o homem que está acostumado a conceber como extra-humanos os poderes sobre os quais ele se apóia. Mas, se ele vier a aceitar que a humanidade por si própria pode lhe fornecer o suporte que precisa, não há nesta perspectiva algo altamente tranqüilizador, uma vez que os recursos que ele exige estão localizados, portanto na porta de sua casa e, por assim dizer, na sua mão? (Durkheim 2002: 7,8, tradução nossa).

Poderíamos também nos lembrar de Georg Simmel e das suas preocupações com a dimensão de crise assumida pela cultura moderna. A sua opinião é muito semelhante à de Durkheim. Em 1916, Simmel comentava:

In our present context the essential fact is the existence of large social groups who, in pursuit of their religious needs, are turning away from Christianity... the widespread rejection of any fixed form of religious life is in keeping with our general cultural situation. Thus supradenominational mysticism has by far the strongest appeal to these groups. For the religious soul hopes to find here direct spontaneous fulfillment, whether in standing naked and alone, as it were, before its God, without the meditation of dogma in any shape or form, or in rejecting the very idea of God as a petrefaction and an obstacle, and in feeling that the true religion of the soul can only be its own inmost metaphysical life not moulded by any forms of faith whatever. (Simmel 1997: 95)

Portanto, em termos contemporâneos, seja qual for o formato assumido - moderno ou pós-moderno, para não citarmos outros - o fenômeno religioso detém o espírito e a alma do indivíduo no seu centro gravitacional. Se Durkheim, há um século, nos oferecia a consciência coletiva e os momentos de efervescência criadora como as bases da religião, atualmente nos vemos diante das possibilidades de uma busca interior, que se empenha em desenvolver a auto-identidade e o potencial humano. 
That unsharable feeling which each one of us has of the pinch of his individual destiny as he privately feels it rolling out on fortune's wheel may be disparaged for its egotism, may be sneered at as unscientific, but it is the one thing that fills up the measure of our concrete actuality, and any would-be existent that should lack such a feeling, or its analogue, would be a piece of reality only half made up. (James 1987: 447)

Inúmeros autores, como vimos anteriormente, apontam para a subjetivação do fenômeno religioso em um franco processo de desregulação e desinstitucionalização da religião. Todavia, em qualquer esforço de definição do fenômeno religioso, é importante que se reconheça as suas múltiplas dimensões. Esta ressalva é feita por Clifford Geertz (Geertz, 2001: 164) quando este salienta que a religião não deve ser reduzida à "experiência", uma vez que, na vida em sociedade, esta dimensão está ligada a outras como o "sentido", a "identidade" e o "poder". Geertz também coloca que, embora o movimento das identidades religiosas e das questões religiosas em direção ao centro da vida social constitua um processo em disseminação, tanto em escala quanto em importância, este processo não ocorre de maneira uniforme. O analista deve estar atento, portanto às inúmeras variedades e expressões do fenômeno religioso.

Uma das mais emblemáticas expressões do fenômeno religioso na atualidade são as peregrinações. Imagens midiáticas de religiosos ou não, atravessam as mais diversas fronteiras, cristalizando a peregrinação como símbolo do mundo contemporâneo, para diversos autores (Bauman, Clifford, entre outros.). O que esses deslocamentos têm de tão íntimo com a modernidade é a força simbólica da experiência religiosa que viabiliza a busca interior. O movimento na busca por si, encontro consigo mesmo. Para ilustrar essa viagem identitária e como ela se realiza em cenários contemporâneos, oferecemos relato de um peregrino moderno.

De família de romeiros de ambos os lados, materno e paterno, sendo uma das suas avós afilhada de Padre Cícero, Joaquim nasceu no Crato, cidade vizinha a Juazeiro do Norte. Esta cidade é apenas o lugar de seu registro de nascimento, que coincidiu com a transferência de seu pai, funcionário público estadual, para ela. Lembra que seu pai, quando ainda vivo, comentava, vez ou outra, que não deveria tê-lo registrado lá. Para ele não fazia sentido. Joaquim conta que foi como romeiros que seus avós paternos e maternos chegaram a Juazeiro. No caso de seus avós paternos, foi Padre Cícero que indicou a direção onde deveriam fixar residência. Seguiram, então, a direção apontada por Cícero e fixaram-se em Palmeirinha, distrito de Juazeiro. Depois de alguns anos, a família mudou-se para a sede desta cidade.

Joaquim contou ainda que a sua família não tinha muitos recursos e que moravam próximos ao Salesiano. O pai, muito religioso, participava de um grupo de oração na periferia da cidade, e mantinha relação estreita com os padres Salesianos que costumavam freqüentar a sua casa. Dessa relação com os padres foi possível viabilizar os estudos de Joaquim no colégio confessional Salesiano. Dependendo de quem era o diretor no ano letivo, o pai de Joaquim conseguia descontos que chegavam até $50 \%$ da mensalidade. Advindo de famílias de católicos tradicionais dos dois lados, Joaquim conviveu com o desejo de que se tornasse padre. De fato, tornou-se coroinha 
logo cedo, não completando, entretanto, o destino sonhado para ele. O desejo foi logo sendo repassado para outros primos. Ao que parece, um primo hoje cumprirá o destino traçado para ele.

Contou ainda que apenas seu tio materno converteu-se a outra religião, "Espiritismo" - fato que provocou grande desgosto em sua avó materna, que adoeceu por causa do acontecido. Mas ela vem se recobrando, conta Joaquim, com o apoio e conversas que as filhas vêm mantendo com ela no sentido de aceitar a decisão do filho.

$\mathrm{Na}$ escola, Joaquim sentia-se diferente pela sua condição de classe, que, por sua vez, dava-lhe outra distinção: um tipo de religiosidade vinculada à romaria. Ter o nome Joaquim e ainda ser coroinha eram referências que não gostava de declarar. Havia um sentimento de vergonha, e um profundo desejo, disse ele, de negação dessa identidade religiosa "tradicional".

Joaquim foi crescendo e com o avançar da adolescência nutriu o desejo de sair de Juazeiro, de se fazer diferente. $O$ talento musical o levou à Alemanha várias vezes, e ao Recife. Em Recife,cursou a Universidade - não em música, pois não se identificava com a proposta do curso. Resolveu fazer Ciências Sociais por sua própria trajetória, junto com o pai, nos serviços comunitários ligados à Igreja. Neste momento da entrevista, comenta que, por mais que quisesse se afastar da religião e "da tradição", prosseguia ligado a ela. A própria ida à Alemanha deveu-se também à Igreja, visto ter sido esse o canal institucional que o levou para fora do Brasil.

O tempo e o espaço em Recife são descritos por ele como "neutros". Apesar de hoje reavaliar tal representação, ele entende que esta compreensão deve-se ao fato de que ali pôde exercer a sua individualidade e autonomia. Recife, sendo "neutra", conferiu uma certa liberdade pela possibilidade de individualização, com horários e atividades regidos por ele mesmo. Espaço também considerado "neutro", pois permitia a ele se refazer como desejado, sem a imposição de uma identidade, de uma história, de uma herança cultural. Cidade Grande, espaço moderno que the permitiu refazer-se sob este signo de temporalidade. Joaquim comenta que o ambiente universitário, pelo seu ethos acadêmico de abertura para a diferença, o acolhia na sua individualidade. Apesar de hoje repensar essa neutralidade, visto entender que a universidade é só mais um papel, como o fora para ele a religião tradicional, reafirma que este espaço foi fundamental para trilhar um movimento de busca e descoberta de si. A música, o cinema, o teatro, o curso de ciências sociais, o tarô de Marselha - todas estas referências desterritorializadas. Referências, sobretudo, fora do Catolicismo tradicional, em que se sentia "encampesinado"; referências desterritorializadas, imagens que lhe permitiram a criação de outros espaços de interlocução para a sua construção identitária e que o fizeram jogar-se em movimento e imaginar-se poder ser diferente.

Mas, se para ele definir-se como de Juazeiro é algo redutor, definir-se sem Juazeiro - sem a romaria - é incompleto. Nesse "movimento", como diz, se viu em retorno à Juazeiro tal qual um romeiro. Quis conhecer a romaria, os lugares sagrados, os romeiros. A sua busca de retorno, que define como encontro, "é um movimento que não se completa", mas que encontra compreensão e possibilidade de estabilização de sentidos. Outras buscas, de outros, podem não levar a um encontro. A sua busca é o encontro, encontro com a tradição, parte dele mesmo, ser romeiro. 
No artigo Assessing Modernities: from 'Pre-' to 'Post-' to 'Ultra'-, Kevin Christiano afirma que a situação atual daqueles que professam alguma religião os coloca diante da obrigação de terem que adequar os seus itinerários religiosos aos símbolos e significados - alguns mais religiosos que outros - que a sociedade lhes oferece (Christiano 2007: 52). No mundo contemporâneo, a religião existiria enquanto uma escolha, e não como um tipo de identidade que é assumida no berço ou transmitida num ambiente social hostil a mudanças.

A leitura do cenário atual que é feita por Kevin Christiano é muito pertinente. Além do crescimento daqueles que se confessam ateus, agnósticos ou que não possuem religião em países como a Inglaterra, a França e os Estados Unidos, há também o aumento das posições intermediárias: muitas pessoas abandonam a prática da religião, mesmo declarando que ainda pertencem a alguma confissão, ou que ainda acreditam em Deus. Se pensarmos numa outra dimensão, a escala das crenças em algo além se amplia, ou seja, passam a serem poucos os que acreditam num Deus pessoal e tornam-se muitos aqueles que se identificam com algo semelhante a uma força impessoal. Em outras palavras, é cada vez maior o número de pessoas que professam crenças distantes da ortodoxia cristã. Nesta mesma linha, aumenta o número de religiões não-cristãs, particularmente as que se originam no Oriente, com a conseqüente proliferação das práticas da Nova Era, das visões que buscam ligar o espiritual ao humano e das experiências que vinculam espiritualidade e terapia. Além disso, cada vez mais pessoas se consideram Católicas sem aceitar dogmas fundamentais, ou combinam orientações cristãs com práticas budistas ou até, rezam sem necessariamente ter a certeza de que acreditam. Neste processo, por exemplo, o Cristianismo se vê diante da necessidade de se reformular, seja através de concílios como o do Vaticano II ou de movimentos como a Renovação Carismática.

Verifica-se também, em relação ao pentecostalismo, uma renovação ocorrida nos estudos acerca da conversão religiosa. Nos últimos dez anos, vários pesquisadores brasileiros têm estudado as dinâmicas envolvidas nos processos de mudança de identidades religiosas ocorridos em instituições prisionais e também entre expresidiários (Scheliga 2000, Teixeira 2009). Nestas etnografias, conceitos como o habitus e a sujeição criminal se apresentam como ferramentas fundamentais para compreender a transformação das individualidades. Ainda fora do universo prisional podemos destacar estudos que também apontam na mesma direção. Cristina Cunha (2009) em sua etnografia em favelas cariocas indica a existência de certa ambiguidade entre os setores evangélicos com o universo do tráfico de drogas. Os traficantes buscariam no pentecostalismo proteção religiosa, transformando o antigo cenário das identificações religiosas em que malandros e criminosos eram habitualmente associados ao universo afro-brasileiro. Natividade (2008), por sua vez. identificou também no pentecostalismo fiéis que mantêm relações homoéroticas. O que se pode destacar é que a fé subjetivada e individual, objeto de reflexão em James, não abre mão das relações comunais. 
Apesar das tendências deste cenário, é importante termos um pouco de cautela em relação às leituras que podem ser feitas das tendências atuais. Embora exista um forte componente individualista no cenário atual, isto não quer dizer que o seu conteúdo seja individualizante. Ou seja, ainda são muitas as pessoas que ingressam em comunidades religiosas extremamente festivas, pela razão de ser este o caminho que escolheram para se realizarem espiritualmente. $O$ elemento festivo continua presente em nossas vidas, e é também através deste elemento que a transcendência rompe no cotidiano, não importa o quanto estejamos organizados em torno de um entendimento imanente do mundo. Charles Taylor ressalta este aspecto quando afirma que "people still seek those moments of fusion, which wrench us out of the everyday, and put us in contact with something beyond ourselves." (Taylor op. cit.: 516,517) E neste sentido Durkheim não estaria de todo ultrapassado. A religião pode não ter por efeito "coesão social", mas, a sociabilidade contemporânea parece ainda insistir na existência de uma comunidade moral gerada e mantida por certa energia afetiva. O espetáculo, as festas, os grandes encontros reunindo multidões são os rituais de efervescência do mundo contemporâneo, geradores do que podemos ainda definir como comunidade moral (Taylor 2007). Entender como é possível e do que é fabricada essa moralidade é o grande desafio das Ciências Sociais na atualidade.

A religião, portanto continua a ser "sentimento", "experiência", conforme o argumento apresentado por William James, e no sentido salientado por Geertz em seu artigo $O$ beliscão do destino. Para Geertz, é importante que se diga, muitas das tendências expostas até agora neste ensaio não teriam grande pertinência analítica, uma vez que, conforme ele afirma,

os eventos dos cem anos decorridos desde que James fez suas palestras - duas guerras mundiais, o genocídio, a descolonização, a disseminação do populismo e a integração tecnológica do mundo - menos contribuíam para impelir a fé para dentro, para as comoções da alma, do que para impulsioná-la para fora, para as comoções da sociedade, do Estado e desse tema complexo a que chamamos cultura. (Geertz 2001: 152)

A divergência, contudo, é apenas aparente, pois o que Geertz busca salientar é a dimensão de mobilidade que o fenômeno religioso passou a ter, ao longo do século $X X$, como sua principal característica. É esta condição de mobilidade que se apreende a partir da experiência de Joaquim, que se relaciona com o Juazeiro num movimento marcado pela incompletude. A sua experiência, embora seja marcada por uma sensibilidade comunal, que se apresenta nos seus retornos ao Juazeiro - tal como o "beliscão do destino" pensado por William James, também assume a forma de uma busca, que destaca elementos de autenticidade e individualização. E mesmo que Joaquim não seja um romeiro no sentido dado por aqueles que querem aprisionar o fenômeno religioso contemporâneo em categorias rígidas, ou seja, interrompendo e substituindo a fluidez do fenômeno empírico pela rigidez de certas categorias criadas pelos cientistas sociais, Joaquim é romeiro porque é assim que se apropria da religião de seus avós e de seus pais, ao seu modo e no sentido interior que encontra nesta auto-definição. Ao comentar sobre o processo de subjetivação, Ronaldo Almeida coloca que o trânsito religioso ainda segue em direção ao comunal, que desperta sentimentos, emoções e relações afetivas, de forma que não haveria propriamente abolição de cultos coletivos, mas a subjetivação da experiência e a desistitucionalização da prática (Almeida 2010: 380-81). 
A experiência do religioso que foi ilustrada neste artigo através da trajetória de Joaquim chama a atenção, portanto, para a capacidade individual do sujeito contemporâneo de elaborar seu próprio universo de normas e de valores, sua "linhagem de crença particular", se usarmos a categoria analítica de Danièle Hervieu-Léger (Hervieu-Léger, op. cit.: 27), a partir de sua trajetória individual. Esta possibilidade se impõe na contemporaneidade como um fato sociológico capaz de, inclusive, vencer os esforços reguladores das instituições, que no caso de Joaquim, seriam as referências ao catolicismo tradicional.

Cabe ao analista, por conseguinte - e aqui encerramos nossa discussão - estar atento às relações entre as dinâmicas internas do crer, que correspondem ao desenvolvimento da experiência individual. o papel das interferências externas e os fatores ligados ao ambiente móvel no qual o processo de transmissão de uma identidade religiosa ocorre. É no exame destas relações, tendo o indivíduo como ponto de partida, e reconhecendo a dimensão de mobilidade da religiosidade contemporânea, que as análises sobre a presença da religião nas sociedades modernas fornecerão subsídios importantes para a teoria social deste início de século.

Roberta Bivar Carneiro Campos é PhD pela University of St. Andrews (2001) e professora Departamento de Ciências Sociais e do Programa de Pós-Graduação em Antropologia da

Universidade Federal de Pernambuco.

Eduardo Henrique Araújo de Gusmão é doutor em Antropologia pela Universidade Federal de Pernambuco (2011) e professor assistente no Departamento de Psicologia da 


\section{NOTAS}

1 Uma das tipologias usadas por Charles Taylor no seu livro A Secular Age é a da distinção entre as formas sociais paleo-durkheimianas, neo-durkheimianas e pós-durkheimianas. Para uma breve definição, poderíamos dizer que uma forma social paleo-durkheimiana seria aquela na qual a religião está profundamente disseminada em toda a estrutura social e não chega a constituir uma esfera diferenciada. Charles Taylor toma a Europa medieval como exemplo deste primeiro tipo. No que diz respeito às formas sociais neo-durkheimianas, nestas a religião estaria parcialmente desligada da estrutura social do parentesco, mas expressaria uma identidade social maior. No caso exemplificado pelo autor, este tipo social teria obtido bastante destaque nos EUA do século XIX, a partir das tentativas de grupos católicos e evangélicos de estabelecerem um consenso moral em torno da vocação missionária do país.

2 Seria importante lembrar que Luc Ferry, ao situar o sacrifício enquanto um elemento inerente à moral moderna, está dialogando com os trabalhos dos historiadores das mentalidades dedicados ao nascimento da família moderna. No livro O Homem-Deus, ao tratar do surgimento da vida sentimental, Luc Ferry mostra que o afeto não era o principal fundamento da família tradicional. Para que a afinidade eletiva com o outro constituísse um novo modo de organização familiar, foi necessário que a subjetividade moderna se formasse e que a noção de indivíduo livre se tornasse uma realidade sociológica concreta. Teria sido sobre essa base individualista que se começou a vivenciar o luto de um marido ou de uma esposa, de um filho ou de uma filha como experiências trágicas, que exigiam sacrifícios. 
ALMEIDA, Ronaldo. 2010. "Religião em Transição". In C.B. Martins \& L.F.D.Duarte (eds.) Horizontes das Ciências Sociais. Antropologia. São Paulo: ANPOCS.

BELLAH, Robert. 1964. “Religious Evolution”. American Sociological Review 29: 358-74.

BERGER, Peter. 1985. O Dosse/ Sagrado. São Paulo: Paulus, $3^{\mathrm{a}}$ ed.

BIRMAN, Patrícia. 2003. Religião e Espaço Público. São Paulo: Attar-CNPq, Pronex.

CHRISTIANO, Kevin. 2007. "Assessing Modernities: From Pre- to Post- to Ultra”. In J. Beckford \& N. J. Demerath III (eds.). The Sage Handbook of the Sociology of Religion. London: Sage Publications.

CUNHA, Christina V. 2009. Evangélicos em ação nas favelas cariocas: um estudo socioantropológico sobre redes de proteção, tráfico de drogas e religião no complexo de Acari. Tese de Doutorado em Ciências Sociais. Rio de Janeiro: Universidade Estadual do Rio de Janeiro.

DURKHEIM, Émile. 2002. "L'avenir de la religion”. Disponível em: http://classiques.uqac.ca/classiques/Durkheim_ emile/sc_soc_et_action/texte_4_14/avenir_religion.pdf. Acesso em 25/12/2010.

. 1995. Da Divisão do Trabalho Social. São Paulo: Martins Fontes.

FERRY, Luc. \& GAUCHET, Marcel. 2008. Depois da Religião: o que será do homem depois que a religião deixar de ditar a lei? Rio de Janeiro: DIFEL.

FERRY, Luc. 2007. O Homem-Deus ou O sentido da vida. Rio de Janeiro: DIFEL.

GIUMBELLI, Emerson.2002. O fim da Religião: dilemas da liberdade religiosa no Brasil e na França. São Paulo: Attar. GAUCHET, Marcel. 1997. The Disenchantment of the World: a political history of religion. Princenton University Press.

GEERTZ, Clifford. 2001. "O beliscão do destino: A religião como experiência, sentido, identidade e poder". In Nova Luz sobre a antropologia. Rio de Janeiro: Jorge Zahar.

HEELAS, Paul \& WOODHEAD, Linda.2004. The Spiritual Revolution. Oxford: Blackwell.

HERVIEU-LÉGER, Danièle. 2008. O Peregrino e o convertido: a religião em movimento. Petrópolis: Vozes.

JAMES, William.1987. "The Varieties of Religious Experience”. In W. James Writings 1902 - 1910. New York: The Library of America.

MARX, Karl.1977. Critique to Hegel's Philosophy of Right. Cambridge University Press.

NATIVIDADE, Marcelo. 2008. Deus me aceita como eu sou? Tese de Doutorado. Rio de Janeiro: IFCS/UFRJ.

PIERUCCI, Antônio Flávio \& PRANDI, Reginaldo. 1996. A realidade social das religiões no Brasil. São Paulo: Hucitec.

SCHELIGA, Eva Lenita. 2000. “E me visitastes quando estive preso": sobre a conversão religiosa em unidades 
penais de segurança máxima. Dissertação de mestrado. Florianópolis: UFSC.

SIMMEL, Georg. 1997. "The Crisis of Culture". In D. Frisby \& M. Featherstone (eds.) Simmel on Culture: Selected writings. London: Sage Publications.

TAYLOR, Charles. 2007. A Secular Age. Harvard University Press.

TEIXEIRA, Cesar Pinheiro. 2009. A construção social do "ex-bandido" - um estudo sobre sujeição criminal e pentecostalismo. Dissertação de Mestrado. Rio de Janeiro: UFRJ.

WEBER, Max. 1998. "Sociologia da Religião". In M. Weber Economia e Sociedade Vol. 1. Brasília: Editora da Universidade de Brasília. . 2004. A Ética Protestante e o "Espírito" do Capitalismo. São Paulo: Companhia das Letras. 


\section{Religião em movimento: relações entre religião e modernidade}

RESUMO

Este artigo pretende refletir, de forma não exaustiva, acerca da relação entre religião e modernidade. Parte-se da leitura dos clássicos da sociologia da religião, cotejando-os com as discussões dos autores de maior destaque na temática nas ciências humanas e sociais atuais. Em seguida, ilustra-se, a partir de um caso empírico, uma das possíveis experiências do religioso e o seu significado no mundo contemporâneo. Nas considerações finais, salientam-se alguns pontos das reflexões destacadas na segunda parte do artigo sobre o lugar do religioso no mundo contemporâneo e sua relação com a individualização e a desregulação da crença.

\section{Religion in movement: relationships between religion and modernity} ABSTRACT

This article aims to make a reflection about the relationship between religion and modernity considering the classics of sociology of religion and the works of the major contemporary social thinkers that have approached this issue. Then it approaches, through a case study, one of the possible experiences of the religious domain and its meaning in the contemporary world. The final part presents some thoughts about the place of the religious domain and its relationship with individualism and the deregulation of belief in the contemporary world. KEY-WORDS: religion, modernity, secularization, individualism. 